\title{
Effect of socio-economic status on the prevalence of diabetes mellitus in Indonesia
}

\author{
Amalia Kusumaningrum, Rico Ricardo \\ Department of Economics, Faculty of Economics and Business, University of Pertamina, Jakarta, Indonesia
}

\begin{abstract}
Article Info
Article history:

Received Jun 22, 2021

Revised Nov 9, 2021

Accepted Nov 22, 2021

\section{Keywords:}

Diabetes mellitus

IFLS

Income level

Logistic regression

Socioeconomic status

ABSTRACT

The case of diabetes mellitus in Indonesia shows an increasing trend, especially in the upper socio-economic groups. This study aimed to determine the effect of socioeconomic status on the prevalence of diabetes mellitus in Indonesia using data from the Indonesia family life survey (IFLS). This study was intentionally targeted at individuals aged 15 years and over who are respondents to IFLS-5. Diabetes mellitus becomes the dependent variable, while the independent variables comprise age, gender, education, income, body mass index, and smoking behavior. Logistic regression was performed to determine the potential socio-economic factors associated with diabetes mellitus. The results reveal that socio-economic status influences the prevalence of diabetes mellitus in Indonesia. The higher the income level, the probability of diabetes mellitus increases by 0.466 percent. Meanwhile, individuals who attended university had a 2.86 percent higher probability than individuals with a primary level of education.
\end{abstract}

This is an open access article under the $\underline{C C B Y-S A}$ license.

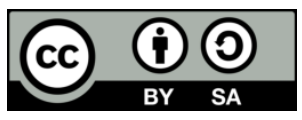

\section{Corresponding Author:}

Amalia Kusumaningrum

Department of Economics, Faculty of Economics and Business, University of Pertamina

Kebayoran Lama, Jakarta, Indonesia

Email: amaliakningrum@gmail.com

\section{INTRODUCTION}

Diabetes mellitus is one of the leading causes of death at the global level. In 2019 there were 1.9 million deaths caused by diabetes mellitus, and almost half of the total deaths (46.2\%) occurred before the age of 60 years [1]. Aside from that, diabetes is one of the fastest-growing chronic diseases in the world. In 2019 , the number of people with diabetes mellitus within the age of 20-79 years reached 463 million, an increase of 8.9 percent from 425 million sufferers two years earlier [1]. The prevalence of diabetes mellitus increases with age, especially in the elderly [2].

In the long term, diabetes mellitus will reduce the quality of life and human well-being of the sufferers. It may cause complications that affect all body organs, such as loss of vision, amputation, kidney failure, heart attacks, and death [3], which eventually may result in loss of work and productivity [4]. Not only detrimental to individuals, diabetes mellitus also causes economic losses. The cost burden that must be borne for diabetes treatment, from the year 2011 to 2030 , is predicted to reach $\$ 1.7$ trillion, including direct and indirect medical costs [5]. Meanwhile, IDF reports that the total cost for its treatment in 2019 reached $\$ 760.3$ billion [1].

In the last few decades, the growth of diabetes mellitus cases has shown a faster development in low and middle-income countries compared to high-income countries [6]. Low and middle-income countries are home to 79.4 percent of people with diabetes in the world [1]. The Southeast Asia region is one of the regions with the highest prevalence of diabetes in the world, whereby Indonesia is the only country in Southeast Asia included in the list of ten countries with the highest diabetes sufferers globally [1], [7]. This indicates that Indonesia's contribution to diabetes cases in Southeast Asia is quite enormous. The number of people with diabetes mellitus in Indonesia continues to increase every year [1]. The increasing prevalence of diabetes in 
Indonesia is a substantial public health issue since it continuously escalates the economic and social burden along with rapid growth in mortality and morbidity. The increasing case of diabetes mellitus in Asia is triggered by rapid economic development, urbanization, and nutrition transition [8]. Indonesia is one of the countries with a relatively rapid urbanization rate [9]. Between 1990 and 2018, the population living in urban areas increased from $31 \%$ to $55 \%$ [9]. The high flow of urbanization due to industrialization and modernization led to an unhealthy lifestyle. The demographic transition in poor and developing countries has changed people's work from the agricultural sector to the industrial sector, resulting in reduced physical activity, triggering obesity, ultimately leading to diabetes [10].

Apart from the increasing number of cases each year in Indonesia, diabetes mellitus has also contributed to a high mortality rate, which ranks in the third position [11]. Based on basic health research (RISKESDAS), the prevalence of diabetes mellitus in each province in Indonesia has increased between 20132018 , with the highest prevalence of diabetes mellitus in the province of DKI Jakarta, and tends to be high among those working in government institutions (i.e. civil servant/army/police/state enterprise) compared to other types of work [12]. Furthermore, those who attend college/university represent the highest proportion of diabetes compared to those with other education levels [12].

These findings are closely related to the upper socio-economic class's lifestyle and the early detection of diabetes cases [13]. A study from India states that, in a wealthy society, the risk of diabetes mellitus is 4.04 times higher than that of a poor community. Besides, individuals who have a higher education level (i.e. college degree) are 1.87 times more at risk than uneducated individuals (i.e. no education) [14]. Many studies related to diabetes mellitus have been carried out in Indonesia. However, these studies rarely use socio-economic status variables as predictors. Thus, this study was designed to determine the effect of socio-economic status on the prevalence of diabetes mellitus in Indonesia.

\section{RESEARCH METHOD}

This cross-sectional study used data from Indonesia family life survey 5 (IFLS-5) published in 2014. IFLS is a large-scale longitudinal survey from the individual and household level for economic, social, educational, and health-related aspects conducted by the research and development (RAND) Labor and Population research institute. The number of respondents in IFLS-5 consists of 16,204 households and 50,148 individuals [15]. Respondents in this study were selected randomly from all of Indonesia's population aged 15 years old and above with diabetes mellitus, which has been diagnosed by the physician in respective health institutions in the study area. A total of 6,979 participants who met the criteria in 2014 were included in the analysis.

The survey classified individuals into diabetic condition and non-diabetic condition. Individuals who self-reported as diagnosed with diabetes were classified as patients with diabetes. Despite being comprehensive, IFLS did not provide any information on the type of diabetes. The main indicators of socioeconomic status in this study were household income and education. The income variable was represented by the individual's income per month, while the participants' education levels were classified into four categories, such as elementary school, junior high school, senior high school, and university. Sociodemographic information, such as age and gender were included as covariates in the analysis model. In addition, risk factors for diabetes, such as body mass index (BMI) and cigarette consumption were included. Body mass index was the accepted method of measuring obesity. Categories of BMI in this study were obesity and non-obesity. Besides, cigarette consumption is calculated based on the number of cigarettes smoked per day. Briefly, the measure was constructed as in Table 1.

Table 1. Statistic description

\begin{tabular}{|c|c|c|c|c|}
\hline \multicolumn{2}{|c|}{ Variable } & Description & \multirow[t]{2}{*}{ Average } & \multirow{2}{*}{$\begin{array}{c}\text { Percentage } \\
98.00\end{array}$} \\
\hline \multirow{6}{*}{ Dependent } & \multirow{2}{*}{ Diabetes Mellitus } & $0=$ No & & \\
\hline & & $1=$ Yes & & 2.00 \\
\hline & \multirow{4}{*}{ Education } & $0=$ Elementary school & & 30.63 \\
\hline & & 1=Junior high school & & 19.20 \\
\hline & & $2=$ Senior high school & & 32.95 \\
\hline & & 3=University & & 17.23 \\
\hline \multirow{8}{*}{ Independent } & Income & Individual income & IDR $1,968,527$ & \\
\hline & Age & Year & 39 & \\
\hline & \multirow{2}{*}{ Gender } & $0=$ male & & 41.70 \\
\hline & & $1=$ female & & 58.30 \\
\hline & Cigarette & Cigarette consumption per day & 13 & \\
\hline & \multirow{2}{*}{ Body mass index } & $0=$ non obesity & & 66.86 \\
\hline & & 1=obesity & & 33.14 \\
\hline & Observation & & & \\
\hline
\end{tabular}

Int J Public Health Sci, Vol. 11, No. 1, March 2022: 281-286 
The collected data were processed and analyzed by using a logistic regression model. Logistic regression was used to analyze the relationship between binary or ordinal response variables and explanatory variables [16]. One of the interpretation methods used in the logistic model is the marginal effect. The marginal effect is a measure of the effect of changes in a dependent variable on the change in probability of outcome [17]. The model was constructed as:

$$
\text { diabetes }_{i}=\beta_{0}+\text { education }_{i}+\text { income }_{i}+\text { age }_{i}+\text { gender }_{i}+\text { BMI }_{i}+\text { cigarette }_{i}+\mu_{i}
$$

\section{RESULTS AND DISCUSSION}

Table 2 shows the marginal effect of the logistic regression. Based on the estimation results, age significantly affects the incidence rate of diabetes mellitus. As a person gets older, the likelihood of having diabetes mellitus increases by $0.417 \%$. The highest risk of a person to develop diabetes mellitus is in the age of 50 to 60 years. The increased risk of diabetes occurs with age due to decreased body functions, including the insulin hormone's metabolism, causing blood sugar levels to increase [18]. The results in Table 2 also indicate that women have 1.15 percent higher probability of having diabetes mellitus than men. These results appear to conform with basic health research (RISKESDAS) in 2018, in which the risk of developing diabetes mellitus in women is greater than that in men [12]. Generally, women have less muscle mass than men, resulting in less glucose uptake in the body [18]. Besides, women tend to have higher stress levels, which can lead to abnormal blood sugar levels [19].

Furthermore, cigarette consumption has a significant and positive effect on the prevalence of diabetes mellitus. It means that for each additional cigarette consumption, the probability of developing diabetes increases by $0.457 \%$ with the assumption of ceteris paribus. The increased risk of diabetes occurs due to the presence of nicotine which causes insulin disorders [20]. The body mass index (BMI) variable also contributes to the incidence rate of diabetes mellitus in a positive direction. The results exhibit that individuals who have a body mass index of obesity have a 0.709 percent higher probability of developing diabetes mellitus than those who are not obese. Generally, people will experience weight gain due to the inability to control their food intake accompanied by inadequate physical activity. Obesity may lead to insulin resistance, which eventually make it harder to control blood sugar levels [21], [22].

Table 2. Marginal effect of logistic regression

\begin{tabular}{lcc}
\hline \multicolumn{1}{c}{ Variable } & Marginal effect & $\mathrm{p}$-value> $|\mathrm{z}|$ \\
\hline Education & & \\
1. Junior high school & 0.00281 & 0.513 \\
2. Senior high school** & 0.0101 & 0.025 \\
3. University*** & 0.0286 & 0.000 \\
Age*** & 0.00417 & 0.000 \\
Age squared*** & $-2.95 \mathrm{e}-05$ & 0.001 \\
Gender & 0.0115 & 0.433 \\
(Log) Income*** & 0.00466 & 0.000 \\
Cigarette consumption* & 0.00457 & 0.082 \\
BMI & 0.00709 & 0.057 \\
\hline cant to $\alpha 1 \%, * *)$ significant to $\alpha 5^{*} \%,{ }^{*}$ ) significant to $\alpha 10 \%$ Total observation: 6,979
\end{tabular}

The socio-economic variables, namely income and education, have a significant positive correlation with the prevalence of diabetes mellitus. The relationship among them cannot be explained directly. Research has found that the relationship between socio-economic factors and diabetes mellitus occurs due to behavioral factors and obesity [23]. In terms of income variable, the marginal effect results show that the higher the individual's income, the probability of developing diabetes mellitus increases by $0.466 \%$. This is consistent with several studies showing similar results that high-income individuals have a greater likelihood of having diabetes mellitus than low-income individuals [14], [24], [25].

There are at least two central arguments why income may affect the incidence of diabetes mellitus in Indonesia. Firstly, individuals with high income are easier to get access to food, including fast food, which is classified as unhealthy [26]. It is different for individuals with low income who are only able to fulfill their basic food needs. High-income people spend more on food than low-income people because people with low incomes have constraints in food affordability [27]. Besides, people with upper-class socio-economic status levels consume more foods that are high in calories and tend not to do physical activity [28]. Secondly, it can be argued that high-income people may have a job that does not require strenuous physical activity. It is different with people with low income, which indicates that they have jobs that require heavier physical 
activity. Individuals with high income have a sedentary lifestyle, in which they spend more time in front of the computer and reading [29].

The education variable also shows significant results. Individuals with a university degree have a 2.86 percent higher probability of developing diabetes mellitus than individuals with primary education. The ascending values of marginal effects with longer education show that the higher the education, the greater the chance of suffering from diabetes mellitus. The results of basic health research (RISKESDAS) in 2018 states that the highest prevalence of diabetes occurs in college graduates [12]. Other studies also show similar results that the probability of diabetes incidence is higher among individuals with high levels of education [30]-[32].

Although highly educated individuals have broader knowledge about health, especially diabetes mellitus, in practice, many people ignore it. Many individuals prefer fast food because that is reasonably practical in their busy life as a student or worker. Women with higher education consume more fast food than others [33]. Students are at risk of adopting a sedentary lifestyle in which they spend most of their time studying in class or on the computer [33]. Individuals with higher education levels also spend more time reading, using computers, and sitting [29]. Other studies have revealed that the transition from school to college is associated with decreased physical activity and an increase in sedentary lifestyle [34]. From these characteristics, it is possible that individuals with higher education levels have a high chance of suffering diabetes mellitus.

If observed further, diabetes mellitus cases that occur in developed and developing countries are different. In developed countries, cases of diabetes mellitus are more common in lower socio-economic classes. On the other hand, diabetes mellitus cases generally affect the upper socio-economic class in poor and developing countries. One reason for this is the differences in the characteristics of the community. First, in developed countries, the price of fast food is relatively lower than healthy food. The majority of consumers are low-income people. Many poor people in developed countries may have diabetes [31]. This reality is different from the case in Indonesia or other developing countries. Fast food is expensive, and only higher income professionals/students can afford it more regularly. They do so because of lack of time to cook. The number of working hours is positively correlated with fast food consumption [35].

Furthermore, developed countries generally have a social support concept in the form of a reasonably healthy work-life balance, so that the stress level of employees is low. This is a stark contrast in developing countries, including Indonesia, which has a low work-life balance. There are still many companies with high workloads and demands that increase stress level which then triggers diabetes. Extreme fatigue experienced by workers will have an impact on decreasing physical condition which can indirectly increase the risk of diabetes [36]. So, it is possible that the growth of diabetes cases in developing countries is relatively faster than in developed countries [6]. Also, developed countries such as the Scandinavian region have a reasonably high happiness index, in contrast to poor and developing countries, including Indonesia, which has a relatively lower happiness index, resulting in disease susceptibility. One's happiness can protect oneself from possible disease [37].

\section{CONCLUSION}

Diabetes mellitus is a dangerous and deadly disease. In Indonesia, this disease continues to increase every year. This study estimates the effect of socio-economic status on the prevalence of diabetes mellitus in Indonesia. After being estimated using logistic regression analysis, it was concluded that socio-economic status significantly affects the incidence rate of diabetes mellitus. The indicators of socioeconomic status in this study are based on the level of income and education. Of the two variables, both the level of income and education positively correlate with diabetes mellitus cases. Based on these estimates, it can be concluded that the higher the income, the greater the chances of developing diabetes mellitus. Furthermore, the higher the level of education will be the higher the chance of developing diabetes mellitus. This study also concludes that other risk factors such as body mass index (obesity), smoking behavior, and individual age positively affects the incidence rate of diabetes mellitus.

Based on the undertaken research, the advice that can be given is to make efforts to prevent diabetes mellitus that are easy to understand and follow by the community. Considering that diabetes cases are prone to occur at the upper-class socio-economic status, socialization can be carried out to companies as well as educational institutions by including health guidelines as a subject curriculum. To support the government's policy, companies should have workplace health initiative. Besides, policymakers also need to increase regular checks, especially regarding blood sugar in middle-aged and older adults.

Int J Public Health Sci, Vol. 11, No. 1, March 2022: 281-286 


\section{ACKNOWLEDGEMENTS}

The authors acknowledge Mr. Achmad Kautsar, Mr. Andika Pambudi, and Mr. Ihsan Ibadurrahman for their valuable advice and helpful suggestions for this study.

\section{REFERENCES}

[1] IDF, "IDF Diabetes Atlas update poster, 9th edn," International Diabetes Federation, 2019. esatlas.org/en/sections/worldwidetoll-of-diabetes.html (accessed Jan. 15, 2021).

[2] F. Chentli, S. Azzoug, and S. Mahgoun, "Diabetes mellitus in elderly," Indian Journal of Endocrinology and Metabolism, vol. 19, no. 6, pp. 744-752, 2015, doi: 10.4103/2230-8210.167553.

[3] K. Al-Rubeaan, "The impact of diabetes mellitus on health and economy of Gulf Cooperation Council countries," Diabetes Management, vol. 4, no. 4, pp. 381-390, Jul. 2014, doi: 10.2217/dmt.14.28.

[4] A. Priyadi, A. Muhtadi, A. A. Suwantika, and S. A. Sumiwi, "An economic evaluation of diabetes mellitus management in South East Asia," Journal of Advanced Pharmacy Education and Research, vol. 9, no. 2, pp. 53-74, 2019.

[5] D. E. Bloom et al., "The Global Economic Burden of Noncommunicable Diseases," 2011. https://www.weforum.org/reports/global-economic-burden-non-communicable-diseases (accessed Jan. 21, 2021).

[6] WHO Global Report, "Global Report on Diabetes," World Health Organization, 2016. https://www.who.int/publications/i/item/9789241565257 (accessed Jan. 17, 2021).

[7] T. Ligita, K. Wicking, K. Francis, N. Harvey, and I. Nurjannah, "How people living with diabetes in Indonesia learn about their disease: A grounded theory study," PLoS ONE, vol. 14, no. 2, p. e0212019, Feb. 2019, doi: 10.1371/journal.pone.0212019.

[8] F. B. Hu, “Globalization of diabetes," Diabetes Care Journal, vol. 34, pp. 1249-1257, 2011, doi: 10.2337/dc11-0442.

[9] United Nations, World Urbanization Prospects 2018, Highlights. New York: Department of Economic and Social Affairs, Population Division, 2018

[10] A. Ramachandran et al., "Temporal changes in prevalence of diabetes and impaired glucose tolerance associated with lifestyle transition occurring in the rural population in India," Diabetologia, vol. 47, no. 5, pp. 860-865, May 2004, doi: 10.1007/s00125004-1387-6.

[11] Y. Usman et al., "Indonesia's sample registration system in 2018: A work in progress," Journal of Population and Social Studies, vol. 27, no. 1, pp. 39-52, 2018, doi: 10.25133/JPSSV27N1.003.

[12] National Institute of Health Research and Development, "Basic Health Research (RISKESDAS) 2018 ," 2018. https://www.litbang.kemkes.go.id/laporan-riset-kesehatan-dasar-riskesdas/ (accessed Jan. 18, 2021).

[13] C. Mutyambizi, F. Booysen, A. Stokes, M. Pavlova, and W. Groot, "Lifestyle and socio-economic inequalities in diabetes prevalence in South Africa: A decomposition analysis," PLoS ONE, vol. 14, no. 1, p. e0211208, Jan. 2019, doi: 10.1371/journal.pone.0211208

[14] D. J. Corsi and S. V Subramanian, "Association between socioeconomic status and self-reported diabetes in India: A crosssectional multilevel analysis," BMJ Open, vol. 2, no. 4, p. e000895, Jul. 2012, doi: 10.1136/bmjopen-2012-000895.

[15] J. Strauss, F. Witoelar, and B. Sikoki, "The Fifth Wave of the Indonesia Family Life Survey: Overview and Field Report: Volume 1," RAND Corporation, 2016. doi: 10.7249/wr1143.1.

[16] D. N. Gujarati and D. C. Porter, Basic Econometrics, Fifth Edit. New York: McGraw-Hill/Irwin, 2013.

[17] C. Y. J. Peng, K. L. Lee, and G. M. Ingersoll, "An introduction to logistic regression analysis and reporting," Journal of Educational Research, vol. 96, no. 1, pp. 3-14, Sep. 2002, doi: 10.1080/00220670209598786.

[18] J. L. Evans and I. D. Goldfine, “Aging and insulin resistance: Just say iNOS,” Diabetes, vol. 62, no. 2, pp. 346-348, Feb. 2013, doi: $10.2337 / \mathrm{db} 12-1239$

[19] A. A. M. et al., "Do Stressed Women have Abnormal Glucose Level?," International Journal of Public Health Science (IJPHS), vol. 6, no. 2, pp. 164-171, Jun. 2017, doi: 10.11591/ijphs.v6i2.6604.

[20] S. A. Chang, "Smoking and type 2 diabetes mellitus," Diabetes and Metabolism Journal, vol. 36, no. 6, pp. 399-403, 2012, doi: 10.4093/dmj.2012.36.6.399

[21] A. S. Al-Goblan, M. A. Al-Alfi, and M. Z. Khan, "Mechanism linking diabetes mellitus and obesity," Diabetes, Metabolic Syndrome and Obesity: Targets and Therapy, vol. 7, pp. 587-591, Dec. 2014, doi: 10.2147/DMSO.S67400.

[22] J. Ye, "Mechanisms of insulin resistance in obesity," Frontiers of Medicine in China, vol. 7, no. 1, pp. 14-24, Mar. 2013, doi: $10.1007 / \mathrm{s} 11684-013-0262-6$

[23] E. D. Williams, R. J. Tapp, D. J. Magliano, J. E. Shaw, P. Z. Zimmet, and B. F. Oldenburg, "Health behaviours, socioeconomic status and diabetes incidence: The Australian Diabetes Obesity and Lifestyle Study (AusDiab)," Diabetologia, vol. 53, no. 12, pp. 2538-2545, Dec. 2010, doi: 10.1007/s00125-010-1888-4.

[24] Z. Wang, X. Li, and M. Chen, "Socioeconomic factors and inequality in the prevalence and treatment of diabetes among middleaged and elderly adults in China," Journal of Diabetes Research, vol. 2018, pp. 1-12, Dec. 2018, doi: 10.1155/2018/1471808.

[25] S. Xu et al., "Prevalence and clustering of cardiovascular disease risk factors among tibetan adults in China: A population-based study," PLOS ONE, vol. 10, no. 6, p. e0129966, Jun. 2015, doi: 10.1371/journal.pone.0129966.

[26] L. Haynes-Maslow and L. A. Leone, "Examining the relationship between the food environment and adult diabetes prevalence by county economic and racial composition: An ecological study," BMC Public Health, vol. 17, no. 1, p. 648, Dec. 2017, doi: 10.1186/s12889-017-4658-0.

[27] S. A. French, M. Wall, and N. R. Mitchell, "Household income differences in food sources and food items purchased," International Journal of Behavioral Nutrition and Physical Activity, vol. 7, no. 1, p. 77, 2010, doi: 10.1186/1479-5868-7-77.

[28] F. C. Pampel, J. T. Denney, and P. M. Krueger, "Obesity, SES, and economic development: A test of the reversal hypothesis," Social Science and Medicine, vol. 74, no. 7, pp. 1073-1081, Apr. 2012, doi: 10.1016/j.socscimed.2011.12.028.

[29] J. Kozo et al., "Sedentary behaviors of adults in relation to neighborhood walkability and income," Health Psychology, vol. 31, no. 6, pp. 704-713, 2012, doi: 10.1037/a0027874.

[30] Y. Bird, M. Lemstra, M. Rogers, and J. Moraros, "The relationship between socioeconomic status/income and prevalence of diabetes and associated conditions: A cross-sectional population-based study in Saskatchewan, Canada," International Journal for Equity in Health, vol. 14, no. 1, p. 93, Dec. 2015, doi: 10.1186/s12939-015-0237-0.

[31] J. Hwang and C. Shon, "Relationship between socioeconomic status and type 2 diabetes: Results from Korea National Health and Nutrition Examination Survey (KNHANES) 2010-2012,” BMJ Open, vol. 4, no. 8, pp. e005710--e005710, Aug. 2014, doi: 10.1136/bmjopen-2014-005710.

[32] K. Suwannaphant, W. Laohasiriwong, N. Puttanapong, J. Saengsuwan, and T. Phajan, “Association between socioeconomic status 
and diabetes mellitus: The national socioeconomics survey, 2010 and 2012,” Journal of Clinical and Diagnostic Research, vol. 11, no. 7, pp. LC18--LC22, 2017, doi: 10.7860/JCDR/2017/28221.10286.

[33] B. H. Hidaka, C. M. Hester, K. M. Bridges, C. M. Daley, and K. A. Greiner, "Fast food consumption is associated with higher education in women, but not men, among older adults in urban safety-net clinics: A cross-sectional survey," Preventive Medicine Reports, vol. 12, pp. 148-151, Dec. 2018, doi: 10.1016/j.pmedr.2018.09.005.

[34] A. P. Crombie, J. Z. Ilich, G. R. Dutton, L. B. Panton, and D. A. Abood, "The freshman weight gain phenomenon revisited," Nutrition Reviews, vol. 67, no. 2, pp. 83-94, Feb. 2009, doi: 10.1111/j.1753-4887.2008.00143.x.

[35] J. L. Zagorsky and P. K. Smith, "The association between socioeconomic status and adult fast-food consumption in the U.S.," Economics \& Human Biology, vol. 27, pp. 12-25, Nov. 2017, doi: 10.1016/j.ehb.2017.04.004.

[36] K. Poulsen, B. Cleal, T. Clausen, and L. L. Andersen, "Work, diabetes and obesity: A seven year follow-up study among Danish health care workers," PLoS ONE, vol. 9, no. 7, p. e103425, Jul. 2014, doi: 10.1371/journal.pone.0103425.

[37] R. Veenhoven, "Healthy happiness: Effects of happiness on physical health and the consequences for preventive health care," Journal of Happiness Studies, vol. 9, no. 3, pp. 449-469, Sep. 2008, doi: 10.1007/s10902-006-9042-1.

\section{BIOGRAPHIES OF AUTHORS}

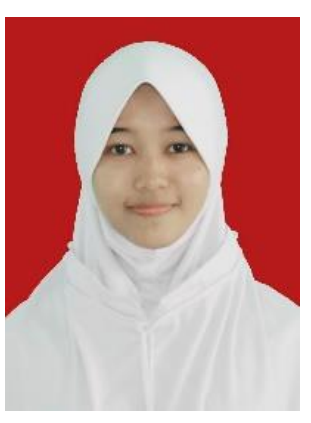

Amalia Kusumaningrum (iD) SC SC $\mathrm{P}$ received her bachelor degree in Economics at University of Pertamina, Indonesia in 2021. Her primary research focuses on health economics and behavioral economics. She has experience in working as a research assistant in the field of energy economics and development of micro, small, and medium enterprises. She has also teaching-assistant experience in econometrics. She can be contacted at email: amaliakningrum@gmail.com.

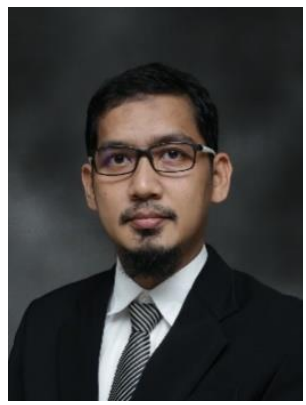

Rico Ricardo (D) If SC P was born in Jakarta. He completed his bachelor degree in Economics from IPB University and his master degree in Economics from International Islamic University Malaysia (IIUM). He, currently, is a member of staff in Economics Undergraduate Programme, Pertamina University. He has taught a number of courses on green and environmental economics over the years. His areas of interest and research are in the energy and environmental economics, and also health and behavioral issues. He can be contacted at email ricoricardo.mec@gmail.com. 